\title{
Lactate dehydrogenase 5 isoenzyme overexpression defines resistance of prostate cancer to radiotherapy
}

\author{
M I Koukourakis ${ }^{*}, 1$, A Giatromanolaki ${ }^{2}$, M Panteliadou ${ }^{1}$, S E Pouliliou ${ }^{1}$, P S Chondrou ${ }^{1}$, S Mavropoulou ${ }^{2}$ \\ and E Sivridis ${ }^{2}$ \\ ${ }^{1}$ Department of Radiotherapy/Oncology, Democritus University of Thrace, Alexandroupolis 68100, Greece and ${ }^{2}$ Department of \\ Pathology, Democritus University of Thrace, Alexandroupolis 68100, Greece
}

Background: Radiotherapy provides high-cure rates in prostate cancer. Despite its overall slow clinical growth, high proliferation rates documented in a subset of tumours relate to poor radiotherapy outcome. This study examines the role of anaerobic metabolism in prostate cancer growth and resistance to radiotherapy.

Methods: Biopsy samples from 83 patients with prostate cancer undergoing radical hypofractionated and accelerated radiotherapy were analysed for MIB1 proliferation index and for lactate dehydrogenase isoenzyme LDH5, a marker of tumour anaerobic metabolism. Ninety-five surgical samples were in parallel analysed. Correlation with histopathological variables, PSA and radiotherapy outcome was assessed. Dose-response experiments were performed in PC3 and DU145 cancer cell lines.

Results: High MIB1 index (noted in 25\% of cases) was directly related to Gleason score $(P<0.0001)$, T3-stage $(P=0.0008)$ and PSA levels $(P=0.03)$. High LDH5 (noted in $65 \%$ of cases) was directly related to MIB1 index $(P<0.0001)$, Gleason score $(P=0.02)$ and T3-stage $(P=0.001)$. High Gleason score, MIB1, LDH5 and PSA levels were significantly related to poor BRFS $(P=0.007,0.01,0.03$ and 0.01, respectively). High Gleason score $(P=0.04)$, LDH5 $(P=0.01)$ and PSA levels $(P=0.003)$ were significantly related to local recurrence. MIB1 and T-stage did not affect local control. Silencing of LDHA gene in both prostate cancer cell lines resulted in significant radiosensitisation.

Conclusions: LDH5 overexpression is significantly linked to highly proliferating prostate carcinomas and with biochemical failure and local relapse following radiotherapy. Hypoxia and LDHA targeting agents may prove useful to overcome radioresistance in a subgroup of prostate carcinomas with anaerobic metabolic predilection.

Prostate cancer is the most common cancer in men. Surgery and radiotherapy offer high-cure rates in cases confined to the prostate gland, with 5-year control rates exceeding 70\% (Kupelian et al, 2002). Extracapsular extension or seminal vesicle involvement, as well as high Gleason score and PSA levels, is, however, linked to high postoperative and post-radiotherapy relapse rates, with longterm control rates falling below 50\% (Galalae et al, 2002; Baccala et al, 2007; Pierorazio et al, 2009).

To improve radiotherapy results, investigation has to consider three main directions. First, normal tissue tolerance has to increase either through technological innovations improving the accuracy of dose distribution or through selective normal tissue cytoprotective agent delivery. Second, the intrinsic radiosensitivity of tumours must be enhanced either by tumour-targeting agents or by radiotherapy quality adjustments, including altered fractionation, particle radiation or hyperthermia. Finally, tumours able to exhibit the accelerated repopulation phenomenon, a complex tumour reaction to radiation damage, should be targeted either with accelerated radiotherapy schemes or with agents, unknown as yet, preventing this very phenomenon. 
Recent clinical radiobiological data have revealed important aspects on the sensitivity of prostate cancer cells, implying low $\alpha / \beta$ ratios (1-2 Gy, (Wang et al, 2003; Fowler, 2005)), and overall better responsiveness to large radiotherapy fractions. Therefore, hypofractionation is a reasonable approach, as indeed randomised trials have shown good local control without increase of toxicities (Yeoh et al, 2011; Dearnaley et al, 2012). Although prostate cancer is generally considered to have low proliferation ability, previous studies have shown increased proliferation rates in a subset of tumours, which indicated failure of conventionally fractionated radiotherapy regimens (Cheng et al, 1999; Li et al, 2004). Hypofractionated and accelerated radiotherapy (HypoARC) may, therefore, be a better therapy option for such subgroups of patients. Clinical trials from our group confirmed the good tolerance and high activity of such regimens (Koukourakis et al, 2011, 2012).

In the current study, we examine whether prostate tumours with high cancer cell MIB1 proliferation index or hypoxic tumours with high glycolytic rates as assessed by the overexpression of the lactate dehydrogenase LDH5 isoenzyme (Koukourakis et al, 2003) affect the outcome of prostate cancer patients treated with HypoARC. In vitro experiments with the PC 3 and DU145 prostate cancer cell lines were also performed to further investigate the role of LDHA gene in prostate cancer radioresistance.

\section{MATERIALS AND METHODS}

Archived formalin-fixed paraffin-embedded tissues from 83 biopsy specimens from prostate cancer patients treated with radical radiotherapy (with or without androgen deprivation) were retrieved from our pathology department. An additional 95 surgical specimens from prostate cancer patients treated with radical prostatectomy were retrieved to form a control base with surgical (larger) tissue samples to validate the reliability of immunohistochemical marker assessment in bioptic material and their correlation with histopathological variables. The study has been approved by the Democritus University of Thrace Research and Ethics Committee. Details on the technique and results of hypofractionated and accelerated radiotherapy with amifostine cytoprotection (HypoARC) have been previously reported (Koukourakis et al, 2011, 2012). Briefly, a total of 15 fractions or $3.5 \mathrm{~Gy}$ per fraction is delivered within 19 days to the prostate and seminal vesicles. Patients with PSA $>10 \mathrm{ng} \mathrm{ml}^{-1}$ or Gleason score $\geqslant 7$ also receive pelvic irradiation (concomitant boost technique: $2.7 \mathrm{~Gy} \times 14$ fractions to the pelvis and $0.8 \mathrm{~Gy}$ to the prostate and seminal vesicles followed by a 15 th fraction of $3.5 \mathrm{~Gy}$ confined to the prostate area).

Out of 178 cases, $152(85.4 \%)$ had disease confined to the prostate gland (T1,2-stage) and 26/178 (14.6\%) had extracapsular or seminal vesicle extension (T3-stage). The above staging was pathological for patients treated with surgery, and was based on biopsy, CT and MRI pelvic and prostate imaging for patients treated with radical radiotherapy. The presence of distant metastasis was assessed with CT scan of the chest and abdomen and with bone scintigraphy. Patients with histologically confirmed node involvement or radiological evidence of node or distant metastasis were excluded from the study. None of the patients undergoing radiotherapy had radiologically confirmed enlarged nodes; the presence of extraprostatic involvement was assessed with CT and MRI imaging. The Gleason score ranged from 4 to 10 (median 5). A low Gleason score of 4-5 characterised 96/178 (53.9\%) cases, a medium of 6-7 characterised 51/178 (28.7\%) and a high score of $8-10$ characterised $31 / 178$ cases $(17.4 \%)$. Pre-radiotherapy maximum PSA levels were also available, ranging from 3.3 to 52 (median 10). ROC analysis of PSA levels against biochemical relapse following radiotherapy showed a specificity value $>70 \%$ for PSA levels $>15 \mathrm{mg} \mathrm{ml}^{-1}$ and this was used as a cutoff point (low vs high). Pre-operative PSA levels ranged from
2.1 to 22 (median 9.1). A detailed report o f patient and histopathological characteristics of tumours in the radiotherapy and surgery groups is shown in Table 1.

The median follow-up of patients treated with radiotherapy was 36 months (range 6-75). The minimum follow-up for patients alive was 24 months. PSA levels were assessed every 6 months. Within the available follow-up time interval, biochemical failure was recorded in $12 / 83$ patients $(14.4 \%)$. In these patients, CT scans of the chest, abdomen and pelvis, a bone scintigraphy, transrectal colour Doppler ultrasonography and prostate MRI were performed in an attempt to identify local or distant relapse. Out of 83 patients, local recurrence could be confirmed in $6(7.2 \%)$ patients ( 3 of them with concurrent confirmation of distant metastasis).

Immunohistochemistry. The prostate carcinomas were stained immunohistochemically for the MIB1 protein using the automated Bond-max system (Leica Microsystems, San Diego, CA, USA). Sections of size $3 \mu \mathrm{m}$ were cut from formalin-fixed paraffinembedded tissues and dried for $30 \mathrm{~min}$ at $80^{\circ} \mathrm{C}$. The slides were then covered by Bond Universal Covertiles (Leica Microsystems) and placed into the Bond-max instrument. This was followed by deparaffinisation of tissue on the slides with Bond Dewax Solution (Leica Microsystems) at $72{ }^{\circ} \mathrm{C}$ for $15 \mathrm{~min}$; heat-induced antigen retrieval with Bond Epitope Retrieval Solution 2 (Leica Microsystems) for $30 \mathrm{~min}$ at $100^{\circ} \mathrm{C}$; peroxide block placement on the slides for $5 \mathrm{~min}$ at room temperature; and incubation with the MIB1 primary antibody (DAKO, Glostrup, Denmark) at a dilution of $1: 75$ for $20 \mathrm{~min}$. The subsequent steps of the procedure were performed at room temperature and included: incubation with Post Primary reagent (Leica Microsystems) for $10 \mathrm{~min}$. Colour was developed using 3,3'-diaminobenzidine tetrahydrochloride (DAB). The sections were then counterstained with hematoxylin for $5 \mathrm{~min}$, dehydrated and mounted. Normal immunoglobulin-G was substituted for the primary antibody as negative control.

For LDH5 immunohistochemistry, sections of $3 \mu \mathrm{m}$ thickness were deparaffinised and placed in antigen retrieval target solution of $\mathrm{pH} 9.0$ (DAKO), followed by microwaving $(3 \times 5 \mathrm{~min})$. Non-specific binding was blocked in normal rabbit serum at a

\begin{tabular}{|c|c|c|c|}
\hline Parameter & $\begin{array}{l}\text { All cases } \\
\text { (178 pts) }\end{array}$ & $\begin{array}{l}\text { Radiotherapy } \\
\text { (83 pts) }\end{array}$ & $\begin{array}{l}\text { Surgery } \\
\text { (95 pts) }\end{array}$ \\
\hline Age (median, range) & $68(44-88)$ & $69(52-79)$ & $63(44-75)$ \\
\hline \multicolumn{4}{|l|}{ T-stage ${ }^{a}$} \\
\hline $\begin{array}{l}\text { T1, } 2 \\
\text { T3 }\end{array}$ & $\begin{array}{r}152(85.4) \\
26(14.6)\end{array}$ & $\begin{array}{c}75(90.3) \\
8(9.7)\end{array}$ & $\begin{array}{l}77(81.0) \\
18(19.0)\end{array}$ \\
\hline \multicolumn{4}{|l|}{ N-stage ${ }^{a}$} \\
\hline $\begin{array}{l}\mathrm{NO} \\
\mathrm{N}+\end{array}$ & $\begin{array}{c}178(100) \\
0(0)\end{array}$ & $\begin{array}{c}83(100) \\
0(0)\end{array}$ & $\begin{array}{c}95(100) \\
0(0)\end{array}$ \\
\hline \multicolumn{4}{|l|}{ Gleason score } \\
\hline $\begin{array}{l}4-5 \\
6-7 \\
8-10\end{array}$ & $\begin{array}{ll}96 & (53.9) \\
51 & (28.7) \\
31 & (17.4)\end{array}$ & $\begin{array}{l}42(50.6) \\
26(31.3) \\
15(18.1)\end{array}$ & $\begin{array}{l}54(56.8) \\
25(26.3) \\
16(16.9)\end{array}$ \\
\hline \multicolumn{4}{|c|}{ PSA levels (mg ml ${ }^{-1}$ ) } \\
\hline $\begin{array}{l}<10 \\
10-15 \\
>15\end{array}$ & $\begin{array}{l}94(52.8) \\
32(18.0) \\
52(29.2)\end{array}$ & $\begin{array}{l}43(51.8) \\
12(14.5) \\
28(33.7)\end{array}$ & $\begin{array}{ll}51 & (53.7) \\
20 & (21.1) \\
24 & (25.3)\end{array}$ \\
\hline \multicolumn{4}{|c|}{$\begin{array}{l}\text { Abbreviations: PSA = prostate-specific antigen; pts = patients. } \\
{ }^{\mathrm{a}} \mathrm{T} \text { and } \mathrm{N} \text { staging refers to pathological staging for patients treated with surgery and to } \\
\text { biopsy and radiological (CT and MRI) staging for patients treated with radical radiotherapy. }\end{array}$} \\
\hline
\end{tabular}


dilution 1:20 for $30 \mathrm{~min}$ (DAKO, X0902). No rinsing was performed. The primary sheep polyclonal antibody to LDH5 isoenzyme (ab9002, Abcam, Cambridge, UK) was applied at a dilution $1: 200$ overnight at $4{ }^{\circ} \mathrm{C}$. Following washing with PBS, endogenous peroxidase was quenched with Peroxidase Block (code: K0679, DAKO) for $10 \mathrm{~min}$. It was followed by washing with PBS. Sections were then incubated with a secondary antibody (Biotinylated Secondary rabbit-antisheep; DAKO, P0163) at 1:100 for $30 \mathrm{~min}$, and washed in PBS. Streptavidin-HRP (K0679, Dako) was applied for $30 \mathrm{~min}$, and sections were again washed in PBS. The colour was developed by $15 \mathrm{~min}$ incubation with $\mathrm{DAB}$ solution, and sections were counterstained weakly with haematoxylin. Normal immunoglobulin-G was substituted for the primary antibody as negative control.

The percentage of cells with nuclear MIB1 expression was assessed in all available fields ( $\times 200$ magnification) and the mean value was used to score each case. The pattern of LDH5 expression in prostatic cancer cells is mixed nuclear and cytoplasmic. The proportion of tumour cells expressing cytoplasmic or nuclear reactivity to LDH5 was separately recorded after examining the entire tumour area at $\times 200$ magnification. A previously reported grading system, combining both nuclear and cytoplasmic expression, was used to score cases as negative, bearing low or high LDH5 reactivity (Koukourakis et al, 2009, 2011). Briefly, tumours with strong cytoplasmic expression in $>50 \%$ of cancer cells and/or tumours with nuclear expression in $>10 \%$ of cancer cells were considered to have high LDH5 reactivity. For MIB1 index, the 5\% value (median value in the radiotherapy biopsy samples) was used to group cases as of high or low proliferation index.

In vitro experiments. Human prostate cancer cell lines PC 3 and DU145 (CLS Cell Lines Service, GmbH, Eppelheim, Germany) were cultured and maintained using standard procedures. Four LDHA siRNAs were custom synthesised (GenePharma Co, Shanghai, China), pooled and used at $50 \mathrm{~nm}$ to transfect cancer cells using HiPerfect (QIAGEN, Gaithersburg, MD, USA) for $24 \mathrm{~h}$; the silencing efficiency of siRNAs was confirmed both by western blot after $48 \mathrm{~h}$ in total.

For immunoblotting, whole-cell lysates from both cell lines were prepared in RIPA buffer (Sigma-Aldrich Chemie Gmbh, Munich, Germany; cat. no. R0278) with the complete mini protease inhibitor cocktail (Roche Diagnostics, $\mathrm{GmbH}$ ) and phosphatase inhibitor cocktail (Cell Signaling Technology Inc.). Proteins of each lysate $(20 \mu \mathrm{g})$ were resolved by discontinuous SDS gels using $10 \%$ separating and $5 \%$ staking gels and transferred to a PVDF membrane (pore size: $0.45 \mu \mathrm{m}$, Millipore Corp., cat. no. IPVH00010). All different experimental condition lysates were loaded on the same gel and transferred on the same membrane. Following blocking with TBS ( $\mathrm{pH} 7.5)$ containing $0.1 \%(\mathrm{v} / \mathrm{v})$ Tween 20 and 5\% (w/v) non-fat dried milk for $2 \mathrm{~h}$ at room

temperature, membranes were hybridised at $4{ }^{\circ} \mathrm{C}$ overnight with the primary sheep polyclonal anti-LDH5 antibody (1:5000, Abcam; cat. no. ab9002). The membranes were then hybridised for $2 \mathrm{~h}$ at room temperature with the secondary antibody, rabbit polyclonal to sheep $\operatorname{IgG}(\mathrm{H}+\mathrm{L})$-HRP conjugate (1 : 10 000; DAKO, Denmark; PO163). Each of these blots was then stripped $(1.5 \% \mathrm{w} / \mathrm{v}$ glycine, $0.1 \% \mathrm{w} / \mathrm{v}$ SDS, $1 \% \mathrm{v} / \mathrm{v}$ Tween $20, \mathrm{pH} 2.2$ ) twice for $10 \mathrm{~min}$, washed twice with PBS for $10 \mathrm{~min}$ each and washed twice with TBS-T for $5 \mathrm{~min}$, at room temperature. Then the blocking stage took place, as described previously, followed by reprobing of the membranes with a rabbit primary anti-beta actin antibody (1:5000, Abcam; cat. no. ab75186) to confirm equal loading of the gels. The secondary antibody used was the goat polyclonal to rabbit IgG $(\mathrm{H}+\mathrm{L})$-HRP conjugate at a dilution of 1:15000 (Biorad, Hercules, CA, USA; cat. no.170-6515). The images of the blots were captured utilising Chemidoc MP imaging system (Biorad), and they were analysed by the accompanied Image Lab software.

For cell survival experiments, cells were placed in 96-well plates at a concentration of 250 cells per well for DU145 and 500 cells per well for PC3 (lower proliferation rates). Irradiation of plates was performed using a 6-MV beam of a Linear Accelerator (PRECISE; ELEKTA) endowed with MultiLeaf Collimator. For multidose irradiation of columns of wells within the same 96-well plate,

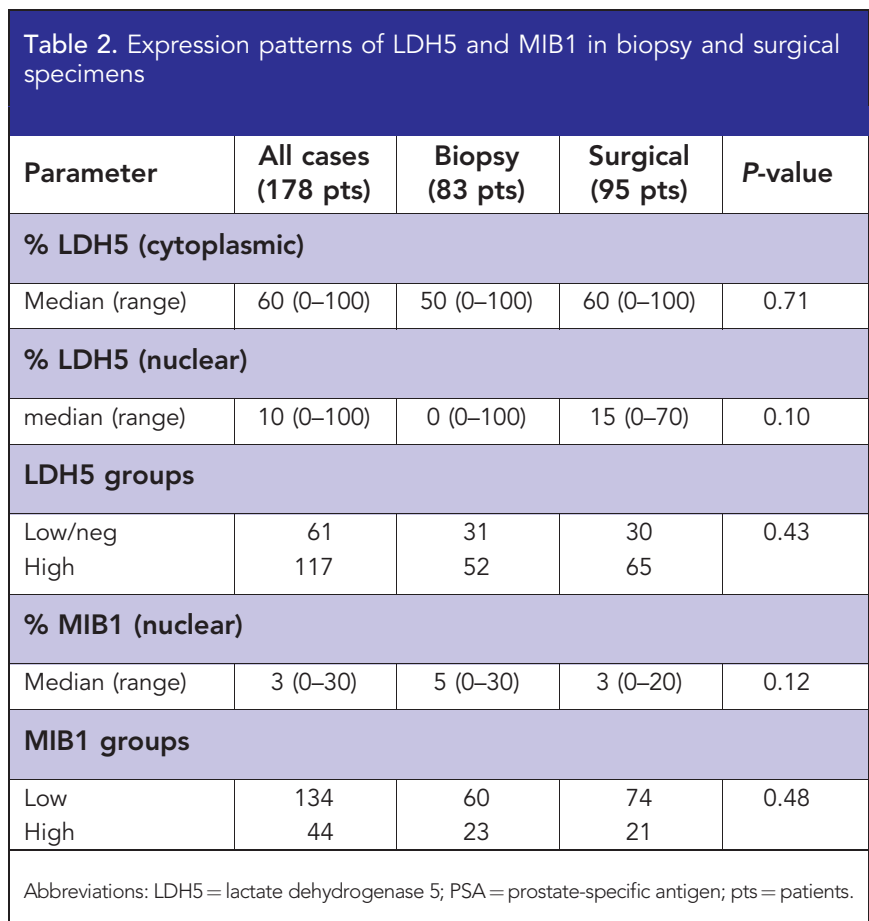
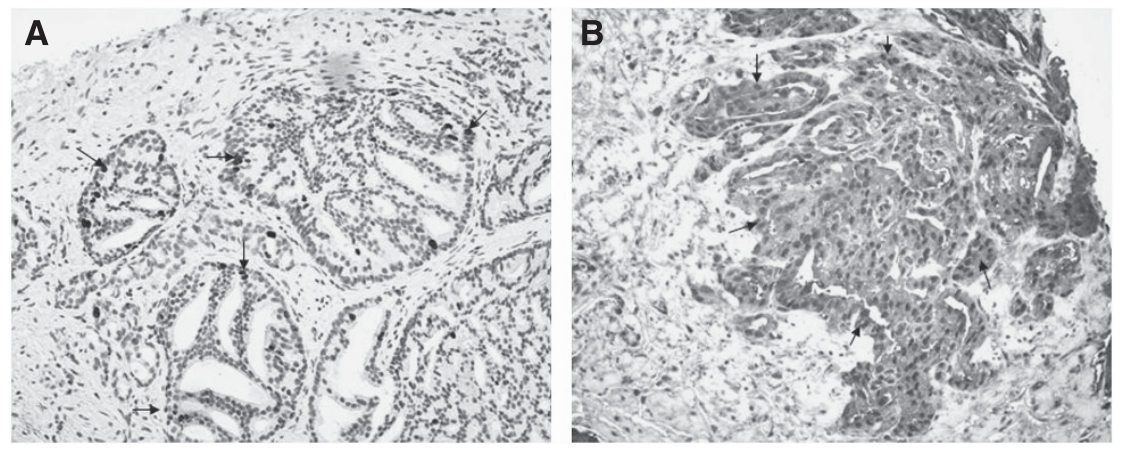

Figure 1. Immunohistochemical expression of MIB1 in the nuclei (A) and of LDH5 in the cytoplasm and nuclei (B) of prostate cancer cells (magnification $\times 200$ ). 
a previously validated and reported technique was used (Abatzoglou et al, 2013). Cell proliferation and survival experiments were performed using the AlamarBlue assay (Serotec; cat. no. BUF012B), as previously validated by our group (Zachari et al, 2013). A microplate reader (FLUOstar Omega; BMG LABTECH $\mathrm{GmbH}$, Ortenberg, Germany) was used to assess fluorescence. At measurement, gain adjustment is performed against the well of the maximum fluorescence (wells with alamarblue and vitamin $\mathrm{C}$ ). The relative fluorescence units (RFU) are recorded for each well at a chosen time point. For every irradiated well the RFU ratio is calculated as follows:

$$
\mathrm{RFU}-\text { ratio }=\frac{\mathrm{RFU} \text { irradiated RFU negative controls }}{\mathrm{RFU} \text { nonirradiated RFU negative controls }}
$$

The mean RFU-ratio value is calculated for all wells receiving the same radiation dose. Survival curves are produced plotting radiation dose (Gy) against mean RFU ratio (corresponding to the $\%$ of cell survival).

Statistical analysis. Statistical analysis was performed using the GraphPad Prism 5.0 and the SPSS 15.0 (SPSS Inc., Chicago, IL, USA) packages. All data were considered either as categorical or as continuous variables. ROC analysis was used to define the specificity cutoff value for PSA regarding biochemical relapse. The Fisher's exact $t$-test, chi-square or unpaired two-tailed $t$-test was used to compare categorical variables as appropriate. Linear regression analysis was employed to assess correlations between continuous variables. Biochemical relapse-free (BRFS) and local relapse-free (LRFS) survival was estimated using Kaplan-Meier curves. Curves were compared using the log-rank test (Mantel-Haenszel). A Cox proportional hazard model including all pre-outcome variables was used to further test the independent significance

\section{Table 3. Association of LDH5 and MIB1 with histopathological variables and PSA levels}

\begin{tabular}{|c|c|c|c|c|c|c|c|c|}
\hline \multirow[b]{2}{*}{ Parameter } & \multicolumn{2}{|c|}{ T-stage } & \multicolumn{2}{|c|}{ Gleason score } & \multicolumn{2}{|c|}{ PSA } & \multicolumn{2}{|c|}{ MIB1 } \\
\hline & $1-2$ & 3 & Low/med & High & $\leqslant 15$ & $>15$ & Neg/low & High \\
\hline \multicolumn{9}{|c|}{ (A) Biopsy specimens } \\
\hline \multicolumn{9}{|l|}{ LDH5 } \\
\hline Neg/low & 31 & 0 & 29 & 2 & 24 & 7 & 28 & 3 \\
\hline High & 44 & 8 & 39 & 13 & 21 & 21 & 32 & 20 \\
\hline$P$-value & \multicolumn{2}{|c|}{0.02} & \multicolumn{2}{|c|}{0.04} & \multicolumn{2}{|c|}{0.14} & \multicolumn{2}{|c|}{0.005} \\
\hline \multicolumn{9}{|l|}{ MIB1 } \\
\hline Low & 58 & 2 & 55 & 5 & 44 & 16 & & \\
\hline High & 17 & 6 & 13 & 10 & 11 & 12 & & \\
\hline$P$-value & \multicolumn{2}{|c|}{0.004} & \multicolumn{2}{|c|}{0.0006} & \multicolumn{2}{|c|}{0.03} & & \\
\hline \multicolumn{9}{|l|}{ PSA } \\
\hline$\leqslant 15$ & 53 & 2 & 49 & 6 & & & & \\
\hline$>15$ & 22 & 6 & 19 & 9 & & & & \\
\hline$P$-value & \multicolumn{2}{|c|}{0.01} & \multicolumn{2}{|c|}{0.03} & & & & \\
\hline \multicolumn{9}{|c|}{ (B) Surgical specimens } \\
\hline \multicolumn{9}{|l|}{ LDH5 } \\
\hline Neg/low & 28 & 2 & 27 & 3 & 25 & 5 & 28 & 2 \\
\hline High & 49 & 16 & 52 & 13 & 46 & 19 & 46 & 19 \\
\hline$P$-value & \multicolumn{2}{|c|}{0.04} & \multicolumn{2}{|c|}{0.37} & \multicolumn{2}{|c|}{0.21} & \multicolumn{2}{|c|}{0.01} \\
\hline \multicolumn{9}{|l|}{ MIB1 } \\
\hline Low & 64 & 10 & 66 & 8 & 61 & 13 & & \\
\hline High & 13 & 8 & 13 & 8 & 10 & 11 & & \\
\hline$P$-value & \multicolumn{2}{|c|}{0.02} & \multicolumn{2}{|c|}{0.006} & \multicolumn{2}{|c|}{0.003} & & \\
\hline (C) All case & & & & & & & & \\
\hline LDH5 & & & & & & & & \\
\hline Neg/low & 59 & 2 & 56 & 5 & 49 & 12 & 56 & 5 \\
\hline High & 93 & 24 & 91 & 26 & 67 & 40 & 78 & 39 \\
\hline$P$-value & & & 0. & & & & & 001 \\
\hline MIB1 & & & & & & & & \\
\hline Low & 122 & 12 & 121 & 13 & 105 & 29 & & \\
\hline High & 30 & 14 & 26 & 18 & 21 & 23 & & \\
\hline$P$-value & & & $<0$. & & & & & \\
\hline
\end{tabular}


of variables that proved to be of significance in univariate analysis. A two-tailed $P$-value of $<0.05$ was considered to be significant.

\section{RESULTS}

Expression patterns. LDH5 was expressed in the cytoplasm and the nuclei of cancer cells (Figure 1). Overall, the percentage of cells with strong cytoplasmic reactivity ranged from 0 to $100 \%$ (median $60 \%$ ) among cases. The percentage of cancer cells with nuclear expression ranged from 0 to $100 \%$ (median 10\%). Table 2 shows the detailed analysis in biopsy and surgical specimens. The $\%$ of cells with nuclear MIB1 expression (Figure 1) ranged from 0 to 30 (median 3). Cases are grouped according to the LDH5 and MIB1grading system reported in the methods. There was no statistical difference between radiotherapy (biopsy) and surgery (surgical specimen) groups.

Association among variables. Table 3 reports the association among LDH5, MIB1, T-stage, Gleason score and PSA levels. Overall, high LDH5 was directly related to high MIB1 index $(P<0.0001)$, high Gleason score $(P=0.02)$, T3-stage $(P=0.001)$ and high PSA levels $(P=0.02)$. Similar associations were obtained in the biopsy and surgical specimens separately. MIB1 proliferation index was also directly related to high Gleason score $(P<0.0001)$, T3-stage $(P=0.0008)$ and high PSA levels $(P=0.0002)$.

Linear regression analysis of continuous variables also confirmed a direct association of cytoplasmic LDH5 expression with MIB1 $(P=0.001, r=0.23)$ and with Gleason score $(P=0.001$, $r=0.26)$. A significant association of MIB1 with Gleason score was also noted $(P<0.0001, r=0.43)$.

Biochemical failure and local relapse. Table 4 reports the univariate and multivariate analysis of BRFS (Kaplan-Meier analysis) and of local relapse of patients treated with radiotherapy. High Gleason score, high MIB1, PSA levels and LDH5 were significantly related to poor BRFS $(P=0.007,0.01,0.01$ and 0.01 , respectively). LDH5, together with the PSA levels, was independently related to biochemical failure $(P=0.05$ and 0.03 , respectively). Figure 2 shows the Kaplan-Meier BRFS curves for MIB1 and LDH5.

Regarding local relapse, Gleason score $(P=0.04)$ and, more strongly, high PSA levels $(P=0.003)$ were significantly related to poor local control. LDH5 was also significantly associated $(P=0.03)$. None of the examined variables was an independent predictor in multivariate analysis.

Prostate cancer cell line radiosensitivity. Western blot analysis showed intense expression of LDH5 by both cell lines and effective silencing of the LDHA gene using LDHA siRNAs (Figure 3A). The PC3 cell line was far more resistant to radiation compared with the DU145 one; the $50 \%$ dose response (DR50) met at 11.7 and $4.3 \mathrm{~Gy}$, respectively (Figures $2 \mathrm{~B}$ and $\mathrm{C}$ ). Silencing of LDHA displaced the survival curves to the left in both cell lines, showing an important radiosensitisation. The DR50 was reduced to $8.15 \mathrm{~Gy}$ and to $2 \mathrm{~Gy}$ for the PC3 and DU45 cell lines, respectively (Figure 2B and C).

\section{DISCUSSION}

Although prostate cancer is considered a slowly growing tumour, this certainly does not apply to all cases. High Gleason score, and also advanced local stage, have been associated with high cancer cell proliferation index in several published studies (Vesalainen et al, 1995; May et al, 2007; Fleischmann et al, 2012; Lopez-Beltran et al, 2012). This has been also confirmed in the current study, where a fraction of about $25 \%$ of tumours treated either with
Table 4. Univariate and multivariate analysis of biochemical relapse-free survival (BRFS) and of local relapse

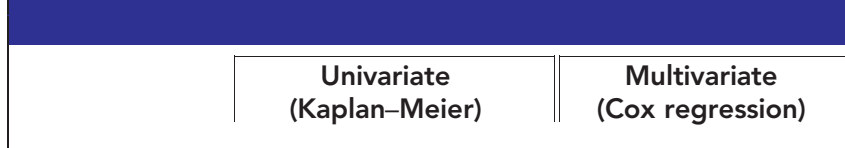

\begin{tabular}{|c|c|c|c|c|}
\hline & Risk ratio & $P$-value & Risk ratio & $P$-value \\
\hline \multicolumn{5}{|c|}{ Biochemical relapse } \\
\hline \multicolumn{5}{|l|}{ Parameter } \\
\hline T-stage & 2.51 & 0.36 & 2.79 & 0.12 \\
\hline Gleason & 8.82 & 0.007 & 1.74 & 0.47 \\
\hline MIB1 & 5.63 & 0.01 & 2.60 & 0.14 \\
\hline LDH5 & 5.12 & 0.01 & 1.88 & 0.05 \\
\hline PSA & 5.10 & 0.01 & 3.30 & 0.03 \\
\hline \multicolumn{5}{|c|}{ Local relapse } \\
\hline T-stage & 2.99 & 0.53 & 1.00 & 0.98 \\
\hline Gleason & 9.10 & 0.04 & 1.30 & 0.21 \\
\hline MIB1 & 3.44 & 0.28 & 1.33 & 0.41 \\
\hline LDH5 & 5.88 & 0.03 & 1.00 & 0.97 \\
\hline PSA & 12.5 & 0.003 & 1.00 & 0.95 \\
\hline
\end{tabular}

radiotherapy or with surgery showed $10-20 \%$ of cancer cells undergoing active cell cycle and, indeed, such tumours were frequently of high Gleason score and expressed extraprostatic involvement.

High proliferation index has also been correlated with increased biochemical failure following prostatectomy (Gunia et al, 2008; Veltri et al, 2008; Minner et al, 2010). In a study by Li et al (2004), on 108 patients who underwent conventional radiotherapy in the context of the RTOG 86-10 protocol, a ki67 proliferation index $>3.5 \%$ was associated with distant metastasis. Several studies also showed that recurrent tumours following radiotherapy bear a higher-than-initial proliferation rate (Grossfeld et al, 1998; Rosser et al, 2003). In our study, high MIB1 index was, indeed, related to high rates of biochemical failure. Local control, however, seemed not to be affected by MIB1, which may show that acceleration of radiotherapy may be an important factor of efficacy in such tumours. Gleason score and high PSA $\left(>15 \mathrm{ng} \mathrm{ml}^{-1}\right)$ levels were the most important factors defining local relapse, implying that such features go along with biological pathways related to intrinsic radioresistance, even to large radiotherapy fractions.

Intratumoral hypoxia may be a component of this resistant tumour biology. In a recent study, direct oxygen measurements of prostate cancer showed that hypoxia was the only factor predictive of local recurrence following radiotherapy (Milosevic et al, 2012). Hypoxia inducible factor 1 is overexpressed in prostate carcinomas (Lekas et al, 2006) and confers radioresistance to prostate cancer cells (Huang et al, 2012; Hennessey et al, 2013). HIF transcriptionally regulates the expression of LDHA gene (Semenza et al, 1996). LDH5 is the isoenzyme composed by 4 LDHA subunits, and has the most potent activity in driving anaerobic cell metabolism to obtain ATP from pyruvate transformation to lactate, in cases where the aerobic pathway is suppressed or impossible to function under the lack of oxygen (Markert, 1984). LDH5 is, therefore, an important marker of intrinsic hypoxia and glycolytic metabolism linked to radioresistance and chemoresistance (Koukourakis et al, 2003, 2009). In the current study, we found that LDH5 is overexpressed in $\sim 65 \%$ of prostate carcinomas and this was directly linked to high Gleason score, proliferation index and extracapsular invasion. A significant association with biochemical 

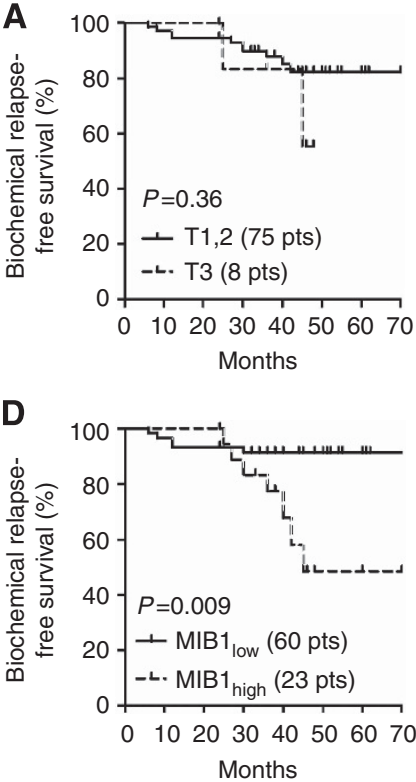
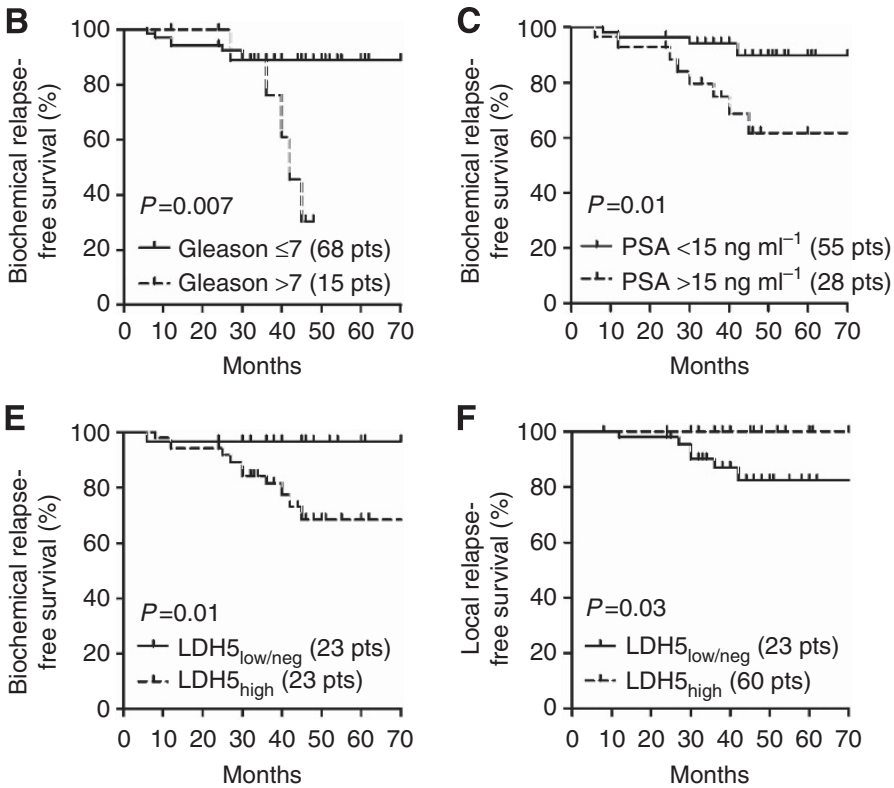

Figure 2. Kaplan-Meier biochemical relapse (a-e) and local relapse-free survival $(\mathrm{f})$ of patients treated with hypofractionated and accelerated radiotherapy stratified for T-stage (A), Gleason score (B), PSA levels (C), MIB1 index (D) and LDH5 expression (E and F).
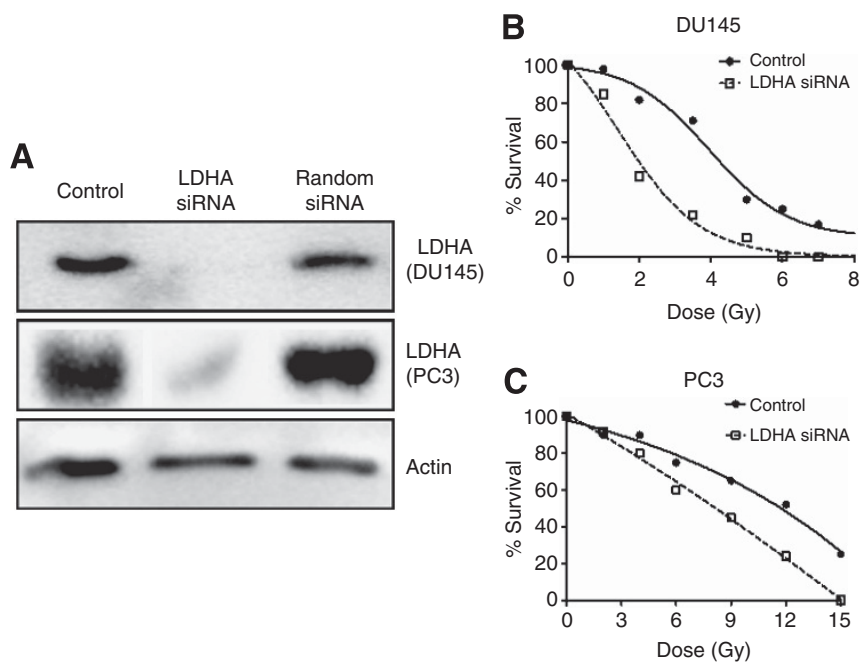

Figure 3. Western blot analysis of LDHA protein expression confirms suppression of LDHA gene using specific siRNAs (A). Such a silencing resulted in important radiosensitisation of PC3 radioresistant $(\mathbf{B})$ and DU145 radiosensitive cell lines (C).

relapse and also with local relapse was observed, which supports the idea that hypoxia and metabolism pathways may underlie the radioresistance of some prostate tumours to radiotherapy, regardless of the fraction size and the overall treatment time. The experimental evidence that HIF inhibitors, such as PX-478, overcome hypoxia-related radioresistance (Palayoor et al, 2008) encourages the combination of such agents with HypoARC. In the current study, silencing of the LDHA gene resulted in important radiosensitisation in two widely used prostate cancer cell lines, namely the PC3 and the DU145.

It is concluded that a high proliferation index, as noted in onefourth of prostate carcinomas, is linked to biochemical failure following radiotherapy. The current study, however, provides evidence that acceleration of radiotherapy may help overcome the ominous effect of both proliferation rate and extracapsular extension on the local tumour control. Hypoxia and anaerobic metabolism may be an important component of prostate cancer radioresistance that counteracts the efficacy of radiotherapy, including hypofractionation. Whether LDHA or hypoxia targeting agents in combination with HypoARC may further improve the efficacy of hypofractionation and of acceleration of radiotherapy is a hypothesis to test in clinical trials.

\section{ACKNOWLEDGEMENTS}

The study has been financially supported by the Tumour and Angiogenesis Research Group.

\section{CONFLICT OF INTEREST}

The authors declare no conflict of interest.

\section{REFERENCES}

Abatzoglou I, Zois CE, Pouliliou S, Koukourakis MI (2013) Establishment and validation of a method for multi-dose irradiation of cells in 96-well microplates. Biochem Biophys Res Commun 431: 456-459.

Baccala Jr A, Reuther AM, Bianco Jr FJ, Scardino PT, Kattan MW, Klein EA (2007) Complete resection of seminal vesicles at radical prostatectomy results in substantial long-term disease-free survival: multi-institutional study of 6740 patients. Urology 69: 536-540.

Cheng L, Sebo TJ, Cheville JC, Pisansky TM, Slezak J, Bergstralh EJ, Pacelli A, Neumann RM, Zincke H, Bostwick DG (1999) p53 protein overexpression is associated with increased cell proliferation in patients with locally recurrent prostate carcinoma after radiation therapy. Cancer 85: 1293-1299.

Dearnaley D, Syndikus I, Sumo G, Bidmead M, Bloomfield D, Clark C, Gao A, Hassan S, Horwich A, Huddart R, Khoo V, Kirkbride P, Mayles H, Mayles P, Naismith O, Parker C, Patterson H, Russell M, Scrase C, South C, Staffurth J, Hall E (2012) Conventional versus hypofractionated high-dose intensity-modulated radiotherapy for prostate cancer: preliminary safety results from the $\mathrm{CHHiP}$ randomised controlled trial. Lancet Oncol 13: 43-54.

Fleischmann A, Huland H, Mirlacher M, Wilczak W, Simon R, Erbersdobler A, Sauter G, Schlomm T (2012) Prognostic relevance of Bcl-2 overexpression in 
surgically treated prostate cancer is not caused by increased copy number or translocation of the gene. Prostate 72: 991-997.

Fowler JF (2005) The radiobiology of prostate cancer including new aspects of fractionated radiotherapy. Acta Oncol 44: 265-276.

Galalae RM, Kovács G, Schultze J, Loch T, Rzehak P, Wilhelm R, Bertermann H, Buschbeck B, Kohr P, Kimmig B (2002) Long-term outcome after elective irradiation of the pelvic lymphatics and local dose escalation using high-dose-rate brachytherapy for locally advanced prostate cancer. Int J Radiat Oncol Biol Phys 52: 81-90.

Grossfeld GD, Olumi AF, Connolly JA, Chew K, Gibney J, Bhargava V, Waldman FM, Carroll PR (1998) Locally recurrent prostate tumors following either radiation therapy or radical prostatectomy have changes in Ki-67 labeling index, p53 and bcl-2 immunoreactivity. J Urol 159: 1437-1443.

Gunia S, Albrecht K, Koch S, Herrmann T, Ecke T, Loy V, Linke J, Siegsmund M, May M (2008) Ki67 staining index and neuroendocrine differentiation aggravate adverse prognostic parameters in prostate cancer and are characterized by negligible inter-observer variability. World J Urol 26: $243-250$.

Hennessey D, Martin LM, Atzberger A, Lynch TH, Hollywood D, Marignol L (2013) Exposure to hypoxia following irradiation increases radioresistance in prostate cancer cells. Urol Oncol 31: 1106-1116.

Huang Y, Yu J, Yan C, Hou J, Pu J, Zhang G, Fu Z, Wang X (2012) Effect of small interfering RNA targeting hypoxia-inducible factor- $1 \alpha$ on radiosensitivity of PC3 cell line. Urology 79(744): e17-e24.

Koukourakis MI, Kyrgias G, Papadopoulou A, Panteliadou M, Giatromanolaki A, Sivridis E, Mavropoulou S, Kalogeris K, Nassos P, Milioudis N, Touloupidis S (2011) Treatment of low-risk prostate cancer with radical hypofractionated accelerated radiotherapy with cytoprotection (HypoARC): an interim analysis of toxicity and efficacy. Anticancer Res 31: 1745-1751.

Koukourakis MI, Papadopoulou A, Abatzoglou I, Panteliadou M, Sismanidou K, Touloupidis S (2012) Postoperative pelvic hypofractionated accelerated radiotherapy with cytoprotection (HypoARC) for high risk or recurrent prostate cancer. Anticancer Res 10: 4561-4568.

Koukourakis MI, Giatromanolaki A, Sivridis E. Tumour and Angiogenesis Research Group (2003) Lactate dehydrogenase isoenzymes 1 and 5: differential expression by neoplastic and stromal cells in non-small cell lung cancer and other epithelial malignant tumors. Tumour Biol 24: 199-202.

Koukourakis MI, Giatromanolaki A, Sivridis E, Gatter KC, Trarbach T, Folprecht G, Shi MM, Lebwohl D, Jalava T, Laurent D, Meinhardt G, Harris AL (2011) Prognostic and predictive role of lactate dehydrogenase 5 expression in colorectal cancer patients treated with PTK787/ZK 222584 (vatalanib) antiangiogenic therapy. Clin Cancer Res 17: 4892-4900.

Koukourakis MI, Giatromanolaki A, Winter S, Leek R, Sivridis E, Harris AL (2009) Lactate dehydrogenase 5 expression in squamous cell head and neck cancer relates to prognosis following radical or postoperative radiotherapy. Oncology 77: 285-292.

Kupelian PA, Elshaikh M, Reddy CA, Zippe C, Klein EA (2002) Comparison of the efficacy of local therapies for localized prostate cancer in the prostate-specific antigen era: a large single-institution experience with radical prostatectomy and external-beam radiotherapy. J Clin Oncol 20: 3376-3385.

Lekas A, Lazaris AC, Deliveliotis C, Chrisofos M, Zoubouli C, Lapas D, Papathomas T, Fokitis I, Nakopoulou L (2006) The expression of hypoxiainducible factor-1alpha (HIF-1alpha) and angiogenesis markers in hyperplastic and malignant prostate tissue. Anticancer Res 26: 2989-2993.
Li R, Heydon K, Hammond ME, Grignon DJ, Roach 3rd M, Wolkov HB, Sandler HM, Shipley WU, Pollack A (2004) Ki-67 staining index predicts distant metastasis and survival in locally advanced prostate cancer treated with radiotherapy: an analysis of patients in radiation therapy oncology group protocol 86-10. Clin Cancer Res 10: 4118-4124.

Lopez-Beltran A, Cheng L, Blanca A, Montironi R (2012) Cell proliferation and apoptosis in prostate needle biopsies with adenocarcinoma Gleason score 6 or 7. 1. Anal Quant Cytol Histol 34: 61-65.

Markert CL (1984) Lactate dehydrogenase biochemistry and function of lactate dehydrogenase. In: Cell Biochemistry and Function, Vol 2, pp 131-134. Butterworth \& Co. (Publishers) Ltd: London, UK.

May M, Siegsmund M, Hammermann F, Loy V, Gunia S (2007) Prognostic significance of proliferation activity and neuroendocrine differentiation to predict treatment failure after radical prostatectomy. Scand J Urol Nephrol 41: $375-381$.

Milosevic M, Warde P, Ménard C, Chung P, Toi A, Ishkanian A, McLean M, Pintilie M, Sykes J, Gospodarowicz M, Catton C, Hill RP, Bristow R (2012) Tumor hypoxia predicts biochemical failure following radiotherapy for clinically localized prostate cancer. Clin Cancer Res 18: $2108-2114$.

Minner S, Jessen B, Stiedenroth L, Burandt E, Köllermann J, Mirlacher M, Erbersdobler A, Eichelberg C, Fisch M, Brümmendorf TH, Bokemeyer C, Simon R, Steuber T, Graefen M, Huland H, Sauter G, Schlomm T (2010) Low level HER2 overexpression is associated with rapid tumor cell proliferation and poor prognosis in prostate cancer. Clin Cancer Res 16: $1553-2560$.

Palayoor ST, Mitchell JB, Cerna D, Degraff W, John-Aryankalayil M, Coleman CN (2008) PX-478, an inhibitor of hypoxia-inducible factor1alpha, enhances radiosensitivity of prostate carcinoma cells. Int J Cancer 123: $2430-2437$.

Pierorazio P, Desai M, McCann T, Benson M, McKiernan J (2009) The relationship between preoperative prostate-specific antigen and biopsy Gleason sum in men undergoing radical retropubic prostatectomy: a novel assessment of traditional predictors of outcome. BJU Int 103: 38-42.

Rosser CJ, Reyes AO, Vakar-Lopez F, Levy LB, Kuban DA, Hoover DC, Lee AK, Pisters LL (2003) Bcl-2 is significantly overexpressed in localized radio-recurrent prostate carcinoma, compared with localized radio-naive prostate carcinoma. 2. Int J Radiat Oncol Biol Phys 56: 1-6.

Semenza GL, Jiang BH, Leung SW, Passantino R, Concordet JP, Maire P, Giallongo A (1996) Hypoxia response elements in the aldolase A, enolase 1, and lactate dehydrogenase A gene promoters contain essential binding sites for hypoxia-inducible factor 1. J Biol Chem 271: 32529-33237.

Vesalainen S, Lipponen P, Talja M, Syrjänen K (1995) Mitotic activity and prognosis in prostatic adenocarcinoma. Prostate 26: 80-86.

Veltri RW, Isharwal S, Miller MC, Epstein JI, Mangold LA, Humphreys E, Partin AW (2008) Long-term assessment of prostate cancer progression free survival: evaluation of pathological parameters, nuclear shape and molecular biomarkers of pathogenesis. Prostate 68: 1806-1815.

Wang JZ, Guerrero M, Li XA (2003) How low is the $\alpha / \beta$ ratio for prostate cancer? Int J Radiat Oncol Biol Phys 55: 194-203.

Yeoh EE, Botten RJ, Butters J, Di Matteo AC, Holloway RH, Fowler J (2011) Hypofractionated versus conventionally fractionated radiotherapy for prostate carcinoma: final results of phase III randomized trial. Int J Radiat Oncol Biol Phys 81: 1271-1278.

Zachari MA, Chondrou PS, Pouliliou SE, Mitrakas AG, Abatzoglou I, Zois CE, Koukourakis MI (2013) Evaluation of the alamarblue assay for adherent cell irradiation experiments. Dose Response (in press); http://doseresponse.metapress.com/media/h07c7jqqvp3qt9qkjj1q/ contributions/m/1/1/3/m11340102g645435.pdf. 